\title{
Integration of information during problem solving due to a meaningful context of learning
}

\author{
RICHARD E. MAYER \\ University of Califormia, Santa Barbara, California $9 \$ 106$
}

\begin{abstract}
Ninety-seven subjects memorized nine associations among six interlocking elements that were presented as links among nonsense letters, connections among spies with word code names (after Hayes, 1966), or airline flights among major US cities. On tests of problem solving and true-false judgments, the letters group and the words group performed nearly identically; however, relative to these two groups, the cities group performed worse or about the same on short recall problems and much better on longer problems requiring chunking of learned information. The conditions and effects of a meaningful learning context for problem solving were discussed.
\end{abstract}

The role of meaningfulness in learning and recall of verbal material has long been a central issue for theories of learning and memory (Ausubel, 1963; Johnson, 1975; Underwood \& Schulz, 1960). One important line of research in this area has suggested that amount of recall is influenced by how well a subject connects new information to concepts already in his cognitive structure. For example, if subjects were instructed to generate their own linking sentences during learning noun paired associates, recall was better than if subjects merely read equivalent linking sentences containing each pair (Bobrow \& Bower, 1969). Similarly, subjects who were instructed to generate a running story using each word during serial learning of noun lists performed better on delayed recall than a yoked control group (Bower \& Clark, 1969; Thieman, 1973). Complimentary results have been obtained using more complex verbal material. For example, if subjects were given a set of proverbs, each followed by an interpretative paraphrase, more of the proverbs were recalled than if subjects were given proverbs followed by repetitive, grammatically transformed, or related sentences (Honeck, 1973). Similarly, subjects who were given a thematic title before reading a metaphorical or technical text passage recalled more than subjects who received the title after reading (Bransford \& Johnson, 1972; Dooling \& Lachman, 1971; Dooling \& Mullet, 1973).

A second line of research has investigated subjects ability to integrate long chains of interlocking verbal

Part of this work was conducted at the Cognitive Institute of Indiana University and part at the Department of Psychology of Indiana University. This research was partially supported by Grant MH-16817 from the National Institute of Mental Health to the Cognitive Institute of Indiana University. The many helpful discussions and ideas provided by Frank Restle and the review of an earlier version of this paper by Peter Poulson are greatly appreciated. Thanks are also due Bill Allen and Jan King, who assisted in preparation of materials and collection of data. Requests for reprints should be sent to Richard E. Mayer, Department of Psychology, University of California, Santa Barbara, California 93106. information. For example, Hayes (1966) asked subjects to memorize a set of pairs of spies who could send oneway messages from the first member of the pair to the second. Since the connections formed an interlocking network, problems required subjects to determine how to get a message from one spy via a sequence of spies to another spy. Hayes' spy problems used unrelated words such as ADJECTIVE to SHOWER, SHOWER to BEEF, etc.

A new question, which attempts to bring these two lines of research closer together, is whether the meaningfulness of the presented materials influences subsequent performance on retention and on inference problems. In particular, the present experiment investigates the idea that an organized, meaningful context for learning a network of connections could result in the ability to integrate or "chunk" long sequences more efficiently. The three contexts used in the present study are: paths among letters located in a forest (letters), connections among spies with word code names (words), and airline flights among U.S. cities located on a map (cities).

Ausubel (1968) has developed a theory based on the idea that learning involves assimilating new information to cognitive structure already existing in the learner's memory, and Mayer and Greeno (1972) have provided some evidence that different outcomes of learning occur depending on the type of cognitive structure to which new information is assimilated during learning. If new technical information such as Hayes' paired associates is assimilated to a narrow set of past experiences-what Ausubel (1968) terms "rote learning set" and Greeno (1973) terms "algorithmic knowledge"-information is likely to be stored in its original format; however, if new information is assimilated to a general organizing set of past experiences ("meaningful learning set" or "propositional knowledge"), a different kind of learning outcome may result. This framework predicts that certain contexts of learning (such as the cities group) allow subjects to encode information within a broader or meaningful learning set, and, hence, will allow sub- 
jects to more easily reorganize and integrate information during subsequent problem solving using that information.

Mayer and Greeno (1975) provided some information on this question by comparing performance on algebra substitution tasks of subjects who learned identical sets of interlocking three-term equations expressed in the form of letters (e.g., $W=O \times D)$ vs. in the form of meaningful situations (e.g., WORK $=$ WEIGHT $\times$ DISTANCE). For both computability judgments and computational problems, the meaningful group performed much faster on longer or more difficult problems but about the same or slower on short problems as compared to the letter group, and there was evidence that the meaningful group was less influenced by the presentation order.

The present study attempted to provide an important extension of the Mayer and Greeno (1975) findings to a new task comparable to Hayes' (1966) task and to deal with a related question concerning the characteristics of meaningful learning. In particular, the present study attempted to clarify Ausubel's (1968) idea, consistent with previous findings (Mayer \& Greeno, 1972), that meaningful learning of new technical information involves assimilation of new information to an existing superordinate structure or schema during acquisition.

There are, however, several alternatives to the assimilation-to-schema theory. For example, word meaning (or familiarity) per se may be responsible for the Mayer and Greeno (1975) results, rather than assimilation to some superordinate cognitive structure. In the present experiment, if familiarity is a critical factor, it would be predicted that the word and cities groups should show the same pattern of performance; if overall context, or "assimilative set" (Ausubel, 1968) is important, then the letter and word groups should show the same pattern of performance, with only the cities group showing the pattern of superiority on long problems described above.

A second alternative is that differences in performance between cities and letter groups could be attributed merely to the fact that only the cities group is presented with a spatially organized map showing the positions of the six cities. Accordingly, it would be predicted that not presenting the spatial map for the cities group or presenting a similar map for the letters group should eliminate any differences among the groups in posttest performance. However, the assimilation-to-schema theory predicts that telling subjects that the nine paths are flights among U.S. cities will allow assimilation of the new material to a "meaninful learning set" even if no map is presented.

A third alternative is that differences in performance between the letter and cities groups is due to different retrieval processes rather than to differences in the acquisition phase. If there were retrieval differences, it would be predicted that telling subjects before or after learning the letter pairs that each of the letters represents a given city should produce the same posttest performance; however, the assimilation-to-schema theory predicts that only the before group would be able to assimilate to a meaninful learning set and, hence, produce superior transfer performance.

A fourth alternative is that apparent differences in posttest integration (or transfer) performance are due to differences in initial learning or in existing associative strengths among elements rather than to qualitative differences in encoding. According to this alternative, it would be predicted that the cities group should perform better on single associations such that superior speed on longer problems is due only to stronger single associations. However, a pattern of disordinal interaction (Bracht, 1970) in which the cities group excels on long problems, but performs worse on single association problems relative to the letter group, is more consistent with the assimilation-toschema prediction of qualitative difference in memory structure.

\section{EXPERIMENT I}

\section{Method}

Subjects and design. Thirty-six subjects were recruited from a pool of introductory psychology students at Indiana University, with 12 subjects in each of three groups. Since all subjects answered the same set of 30 questions, comparisons by type of question are within-subject comparisons.

Materials. Three decks of nine cards each were constructed, with a number 1 through 9 on the front and a pair of letters, words, or cities on the back representing a one-way path (see Table 1).

Separate sets of 30 question cards were constructed to express identical questions in terms of letters, words, or cities.

Table 1

Nine Associations Learned in Three Problem Formats

\begin{tabular}{|c|c|c|c|}
\hline Card Number & $\begin{array}{l}\text { Letters } \\
\text { (Paths) }\end{array}$ & $\begin{array}{c}\text { Words } \\
\text { (Spy Connections) }\end{array}$ & $\begin{array}{c}\text { Cities } \\
\text { (Flights) }\end{array}$ \\
\hline 1 & $\mathrm{C}$ to $\mathrm{N}$ & CLERK to NEIGHBOR & CHICAGO to NEW YORK \\
\hline 2 & $\mathrm{H}$ to $\mathrm{L}$ & HANDLE to LEAGUE & HOUSTON to LOS ANGELES \\
\hline 3 & $\mathrm{~S}$ to $\mathrm{C}$ & SAND to CLERK & SEATTLE to CHICAGO \\
\hline 4 & $\mathrm{~N}$ to $\mathrm{M}$ & NEIGHBOR to MOUTH & NEW YORK to MIAMI \\
\hline 5 & $\mathrm{H}$ to $\mathrm{C}$ & HANDLE to CLERK & HOUSTON to CHICAGO \\
\hline 6 & $L$ to $S$ & LEAGUE to SAND & LOS ANGELES to SEATTLE \\
\hline 7 & $\mathrm{M}$ to $\mathrm{H}$ & MOUTH to HANDLE & MIAMI to HOUSTON \\
\hline 8 & $\mathrm{~L}$ to $\mathrm{C}$ & LEAGUE to CLERK & LOS ANGELES to CHICAGO \\
\hline 9 & $\mathrm{H}$ to $\mathrm{N}$ & HANDLE to NEIGHBOR & HOUSTON to NEW YORK \\
\hline
\end{tabular}


The questions were of two types: "Legs" questions asked the subject how many separate paths were required to complete the shortest trip between two points, and "costs" questions asked subjects to determine the cost of a trip between two points based on the assumption that each leg of a trip costs $\$ 1$ to $\$ 9$, depending on it's card number (see Table 1). The questions also varied in length from one to five legs. For example, a legs-1 problem is, "How many legs from $H$ to $L$ ?" (answer: 1), and a costs-3 problem is, "What is the cost from $H$ to $M$ ?" (answer: $5+1+4=10$ ).

In addition, materials included a subject questionnaire asking about the subject's mathematics experience, a pretest for five algebra substitution problems, a simplified map of the United States showing the six cities used by the cities group, and answer sheets for learning the nine paths and answering the 30 questions.

Procedure. Subjects were randomly assigned to treatments and tested individually. The mean Scholastic Aptitude TestMathematics score, mean pretest score, and mathematical experience were similar for all three groups. After completing the subject questionnaire and pretest, the subject was given the deck of nine path cards appropriate for his or her treatment and an answer sheet numbered 1 through 9 down the left margin. The subject was instructed to write the first path on the appropriate space on the answer sheet, to flip over the top card (marked " 1 "), and to put an " $X$ " if the path indicated on the back of the card was different from what the subject had written, or a " $C$ " if it was correct. Then the subject was to put the first card on the bottom of the deck, cover his/her answers with a card, write the second path on the answer sheet, flip over the next card (marked "2"), and so on. When the subject completed all nine cards, he or she was given a new answer sheet and the procedure was repeated; the subject continued to a criterion of two errorless trials. In addition, subjects were asked to write out the nine paths after reading the directions for the test and aitter the test.

Subjects in the letters group were told the letters represented one-way paths between points in a forest; the words group was told the words represented one-way connections for messages among spies with code names (as in Hayes, 1966, study); and the cities group was told the cities represented oneway airline flights, and was allowed to study a map showing the six cities. The map was returned to the experimenter prior to learning.

Then subjects responded to each of 30 test cards by writing answers on the answer sheet and placing the finished card on a nearby table. The cards were organized in to eight blocks based on type and length (five legs-1, four legs-2, three legs-3, three legs $-4 / 5$, five costs -1 , four costs- 2 , three costs- 3 , three costs$4 / 5)$, and the presentation order of the eight blocks was determined by a Latin square. The experimenter recorded the time to answer each of the eight blocks of problems.

\section{Results and Discussion}

Since the error rates were low (less than 10\%) and evenly distributed among the treatment groups, the response time data (for correct responses) were subjected to an analysis of variance. Table 2 shows the average response time per question for each of eight kinds of questions. The average learning trials to criterion for the letters, words, and cities groups were $5.5,9.0$, and 6.0 , respectively $[\mathrm{F}(2,42)=14.05$, $\mathrm{p}<.001]$; however, there was no reliable difference in learning trials for the letters and cities groups $(t<1)$. There were reliable overall differences among the groups in total time to solve the 30 problems, with the letters and words groups considerably slower than the cities group $[F(2,33)=5.90, p<.01]$. In addition, there was an interesting pattern of performance in which all groups performed at about the same speed for short problems (i.e., Length 1 or 2) but the cities group was much faster than the other groups on long problems (i.e., Length 3, 4, or 5). This pattern occurred for both legs- and cost-type problems, and is reflected in a reliable Group by Length interaction $[\mathrm{F}(2,33)=2.18$, $\mathrm{p}<.01]$.

These findings extend to a task like Hayes' (1966) spy problems, earlier results comparing solving equations presented in letter and story formats (Mayer \& Greeno, 1975), and also provide more information concerning the role of "meaning" in learning and problem solving. (1) The meaningful context provided by a map of six cities may have served as a "meaningful learning set" (Ausubel, 1968)-an organized body of propositional knowledge existing in long-term memory to which new information could be assimilated. The meaningful context seems to have its main influence on integrating long sequences of information in working memory while the context does not aid in retention of specific information; these findings are consistent with the idea that the cities group acquired the nine paths in a more flexible, integrated structure than the other groups. (2) Another important implication follows from the fact that the words group performed almost identically with the letters group. The words, although individually meaningful, did not provide an overall unified context or "learning set" to which new information could be assimilated. Thus, the letters and words groups lacked an organizing system that would allow subjects to use larger "chunks" in working memory. A meaningful context, apparently, is not derived from the sum of individual, isolated word meanings.

\section{EXPERIMENT II}

In Experiment II, subjects responded "yes" or "no" to statements about number of legs or costs of "trips"

Table 2

Mean Time (Seconds) to Answer Problems for Three Groups: Experiment I

\begin{tabular}{|c|c|c|c|c|c|c|c|c|c|c|}
\hline \multirow{2}{*}{$\begin{array}{l}\text { Treatment } \\
\text { Group }\end{array}$} & \multicolumn{4}{|c|}{ Legs } & \multicolumn{4}{|c|}{$\begin{array}{r}\text { Type and Length of Problem } \\
\text { Costs }\end{array}$} & \multicolumn{2}{|c|}{ Total } \\
\hline & 1 & 2 & 3 & $4 / 5$ & 1 & 2 & 3 & $4 / 5$ & $1 / 2$ & $3 / 4 / 5$ \\
\hline Letters & 16 & 24 & 38 & 54 & 18 & 31 & 56 & 70 & 22 & 55 \\
\hline Words & 19 & 25 & 44 & 50 & 19 & 30 & 58 & 81 & 23 & 58 \\
\hline Cities & 12 & 19 & 32 & 29 & 20 & 31 & 33 & 57 & 21 & 38 \\
\hline
\end{tabular}

Note-Standard error of measurement is $4.0 \mathrm{sec}$. 
rather than computing numerical answers as in Experiment I. Experiment II allowed more precise time measurements and allowed for randomization of test items.

\section{Method}

Subjects and design. The subjects were 45 Indiana University students who were paid $\$ 2$ for participating in the experiment. Fifteen subjects served in each of the three treatment groups described in Experiment $I$.

Materials. The same learning decks, subject questionnaire, and pretest were used as in Experiment I. Separate isomorphic sets of 60 questions were constructed for each presentation format in the form, "___ to t__ has legs" or "__ to c__ c_ where the first two blanks are letters, words, or cities and the third blank is a number. Questions varied type (legs or cost) and length (one, two, three, four, or five legs), as in Experiment $I$; in addition, half of the questions had "yes" answers and half had "no." The "no" questions presented the same paths as the "yes" questions, i.e., the first two blanks were the same, but the number given in the third blank was taken from a similar "yes" problem. For example, a legs-1-no question is, " $\mathrm{C}$ to $\mathrm{N}$ has two legs" and a cost-3-yes question is, "M to $C$ costs $\$ 17$."

Procedure. Subjects learned the nine paths as in Experiment I, and pressed a "yes" or "no" button in response to 120 questions that were presented individually on a CRT screen. The order of presentation was 30 randomized legs questions, 30 randomized costs questions, and then a repeat of these. Response times and subjects' answers were recorded by an IBM 1800 computer. Subjects received feedback after each set of 30 questions, as the following appeared on their screen, "You were _..\% correct on the last set of questions. When you are ready for more questions press the button."

\section{Results and Discussion}

In order to reduce the effects of subjects' learning to use the CRT response system, response times for only the final block of 60 questions were analyzed. Error rates were below $10 \%$ for each group, and the pattern of errors was similar for each group. The average learning trials to criterion for the letters, words and cities groups were $5.5,6.7$, and 6.3 , respectively; these differences were only marginally reliable $[F(2,42)=3.20, p<.10]$, and the difference between the letters and cities groups was not significant. $(\mathrm{t}=1.60, \mathrm{df}=28, \mathrm{p}>.20)$.

Table 3 shows the response times for correct responses for the three groups on the final 60 questions, by type and length. As in Experiment I, an analysis of variance revealed overall differences among the groups $[F(2,45)=7.70, p<.01]$ in which the letters and the words groups took longer to respond (14.7 and $13.5 \mathrm{sec}$, respectively) than the flights groups $(9.7 \mathrm{sec})$. In addition, for both legs and costs problems, there was a pattern similar to that obtained in Experiment I: The letters and words groups displayed nearly identical patterns of performance; the cities group responded relatively slower or about the same on short recall problems but progressively faster than the other two groups on longer problems. This observation is reflected in the reliable two-way interaction of Treatment by Length of Problem $[F(8,180)=6.29, p<.001]$ and adds replicatory support for the discussion in Experiment I.

\section{EXPERIMENT III}

A supplemental study was conducted in order to clarify two questions raised by the results of Experiments I and II. One question is whether the cities treatment aided mainly in learning, by providing a meaningful learning set to which new information could be assimilated, or in retrieval during problem solving, by providing a context for rearranging previously learned material. In order to provide some information on this question, all subjects learned the nine paths expressed as letters, but one group (before group) was given a list of the city-letter pairs before learning and one group (after group) received the same list after learning to criterion. A second question is whether the superior integration performance of the cities group resulted entirely from the fact that the cities group was exposed to a spatial array indicating the six cities on a map, while the letters or words groups were not given any array. In Experiment III no maps or other spatial arrays were presented, so that the main variable was whether or not subjects knew before learning that the letters were abbreviations for cities and the paths were airline flights.

\section{Method}

The subjects were 16 students enrolled in introductory psychology courses at the University of California at Santa Barbara, with eight subjects in each treatment group. Groups were equated for Scholastic Aptitude Test-Mathematics score, grade point average, pretest score, and math experience. The materials and procedure were essentially identical to the letters condition of Experiment I except for the following: The description of the task as learning about paths in a forest was eliminated; subjects in the before group received, prior to learning, a list for converting letters to cities (e.g., $C=$ Chicago, $\mathrm{H}=$ Houston, etc.) and a short passage explaining that the letter-to-letter paths were airline flights among cities; and subjects in the after group received the identical list and passage following learning to criterion.

Table 3

Mean Time (Seconds) to Make Judgments for Three Groups: Experiment II

\begin{tabular}{|c|c|c|c|c|c|c|c|c|c|c|}
\hline \multirow{3}{*}{$\begin{array}{c}\text { Treatment } \\
\text { Group }\end{array}$} & \multicolumn{10}{|c|}{ Type and Length of Problem } \\
\hline & \multicolumn{5}{|c|}{ Legs } & \multicolumn{5}{|c|}{ Costs } \\
\hline & 1 & 2 & 3 & 4 & 5 & 1 & 2 & 3 & 4 & 5 \\
\hline Letters & 3.8 & 8.4 & 11.3 & 14.5 & 21.5 & 4.9 & 10.5 & 19.3 & 24.9 & 28.0 \\
\hline Words & 4.7 & 9.9 & 10.7 & 15.7 & 18.7 & 4.9 & 9.9 & 16.1 & 20.2 & 23.7 \\
\hline Cities & 3.9 & 5.2 & 7.6 & 9.0 & 9.3 & 5.6 & 8.4 & 13.0 & 16.7 & 17.8 \\
\hline
\end{tabular}

Note-Standard error of measurement is $.8 \mathrm{sec}$. 
Results and Discussion

The after group averaged 8.0 trials to criterion in learning and the before group averaged 7.0 trials, indicating only a nonsignificant difference in learning difficulty $(\mathrm{t}<1)$. As in previous experiments, error rates were below $10 \%$ and similarly distributed for the two groups. The average times (seconds) per answer on the problems of Length $1,2,3$, and $4 / 5$ (collapsing over type of problem) were $16,28,58$, and 77 , respectively, for the after group, and $16,29,40$, and 39 , respectively, for the before group. Similar patterns were present for each type of problem. An analysis of variance revealed a significant two-way interaction of Group by Length of Problem $[F(3,42)=7.44, p<.001]$, confirming the observation of a pattern in which the two groups performed at almost identical levels for short problems; but the before group excelled on problems requiring integration of longer sequences of learned information.

These results are encouraging for the idea that the superior performance on integrating information is primarily due to assimilation of information to a meaningful set of experiences during learning, rather than to the facilitating effects of a meaningful context used as a retrieval and restructuring aid only during problem solving. Further, these results suggest that the superior performance of the cities group cannot be explained solely by the fact that a spatial array was given to one group but not to others. Further research is warranted and suggested by Polich and Schwartz (1974) to determine the facilitating effects of a spatial array on learning and problem solving.

\section{CONCLUSIONS}

In all experiments, subjects learned nine new associations. For all subjects the internal structure-what we have termed "internal connectedness" (Mayer \& Greeno, 1972)-was identical, based on nine identical relations. However, the present experiment also varied how well the new information was related to existing concepts in the learner's long-term memory-what we have termed "external connectedness."

The main finding of the present three experiments was a consistent interaction between meaningfulness of context and length of problem; the present studies allow further analyses of the assimilation interpretation as compared to alternative interpretations.

\section{Word Familiarity vs. Assimilation}

Since the letters group and words group displayed nearly identical performance in Experiments I and II, there is no evidence that isolated meaningful words provide better "external connections" to a learning set than nonsense letters. However, the cities group displayed a very different pattern from the other two groups, namely, slower or the same on recall but faster on integration of information. This suggests that allowing subjects to relate new information to an integrated, existing body of knowledge during learning (e.g., to a set of six easily organized cities) results in a more integrated learning outcome.

\section{Retrieval vs. Assimilation}

The fact that sequencing of the meaningful context before vs. after learning resulted in different patterns of performance suggests that the structure of "what is learned" is heavily determined by the availability of a meaningful context during learning and may be fairly resilient under different retrieval conditions.

\section{Spatial Organization vs. Assimilation}

Since Experiment III obtained results comparable to those of Experiments I and II, but without using a map for the cities group, there is no evidence that the spatial organization alone served as a meaningful leaming set. Rather, these findings are consistent with the idea that the six cities themselves formed an integrated set for the learner.

\section{Associative Strength vs. Assimilation}

The fact that the cities group (or the before group) performed about the same on retention of initial paths provides some evidence against the idea that differences in inference are due to differences in associative strength. However, since the Context by Length interaction is not disordinal, the associative strength interpretation may not be entirely eliminated.

\section{Initial Learning vs. Assimilation}

Since the cities group and the letters group achieved the learning criterion in approximately the same number of trials, and since the two groups in Experiment III required approximately the same number of trials to learn, and since all subjects achieved overlearning by being able to write out the nine paths before and after the test, there is no evidence that differences in inference performance may be attributed to differences in the degree of learning.

\section{REFERENCES}

Ausubel, D. P. The psychology of meaningtul verbal learning. New York: Grune \& Stratton, 1963.

Ausubel, D. P. Educational psychology: A cognitive approach. New York: Holt, Rinehart, \& Winston, 1968.

Bobrow, S. A., \& Bower, G. H. Comprehension and recall of sentences. Journal of Experimental Psychology, 1969, 80, 455-461.

Bower, G. H., \& Clark, M. C. Narrative stories as mediators for serial learning. Psychonomic Science, 1969. 14, $181 \cdot 182$.

Bracht, G. H. Experimental factors related to aptitudetreatment interactions. Review of Educational Research. 1970, 40, 627-645.

Bransford, J. D. \& Johnson, M. K. Contextual prerequisites for understanding: Some investigations of comprehension and recall. Journal of Verbal Learning and Verbal Behavior. 1972, 11. 717-726.

Dooling, D. J.. \& Lachman, R. Effects of comprehension 
on retention of prose. Journal of Experimental Psychology, 1971, 88, 216-222.

Dooling, D. J., \& Mullet, R. L. Locus of thematic effects in retention of prose. Journal of Experimental Psychology, 1973, 97, 404-406.

Greeno, J. G. The structure of memory and the process of solving problems. In R. Solso (Ed.), Contemporary issues in cognitive psychology: The Loyola symposium. Washington, D. C: Winston, 1973.

Hayes, J. R. Memory, goals and problem solving. In B. Kleinmuntz (Ed.), Problem solving research, method, and theon. New York: Wiley, 1966.

HONECK. R. P. Interpretive versus structural effects on semantic memory. Joumal of Verbal Learning and Verbal Behavior; 1973, 12, 448-455.

Johnson, R. E. Meaning in complex learning. Review of Educational Research. 1975, 45, 425-459.
MaYer. R. E., \& Greeno, J. G. Effects of meaningfulness and organization on problem solving and computability judgments. Memory \& Cognition, 1975, 3, 356-362.

Mayer, R. E., \& Greeno, J. G. Structural differences between learning outcomes produced by different instructional methods. Journal of Educational Psychology, 1972, 63, 165-173.

Polich. J. M.. \& Schwartz, S. H. The effect of problem size on representation in deductive problem solving. Memony \& Cognition. 1974, 2, 683-686.

Theiman, T. J. Levels of processing serial lists embedded in narratives. Joumal of Experimental Psychology, 1973, 100. 423-425.

Underwood. B. J., \& Schulz, R. W. Meaningfulness and verbal learning. Chicago: Lippincott, 1960.

(Received for publication November 14. 1975; revision received March 2, 1976.) 